Supporting Information for

\title{
Study on Properties of Low-Temperature-Prepared Zinc Oxide-Based Inverted Organic Solar Cells and Improvement of their Photo-Durability
}

Masahiro Nakano ${ }^{\dagger *}$, Sae Nakagawa ${ }^{\dagger}$, Fumiya Sato $^{\dagger}$, Md. Shahiduzzaman ${ }^{\ddagger}$, Makoto Karakawa ${ }^{\dagger, \ddagger, \S}$, Tetsuya Taima ${ }^{\dagger, \ddagger, \S}$, Kohshin Takahashit*

†Graduate School of Natural Science and Technology, Kanazawa University, Kakuma-machi, Kanazawa, Ishikawa 920-1192, Japan.

‡Nanomaterials Research Institute (NanoMaRi), Kanazawa University, Kakuma-machi, Kanazawa, Ishikawa 920-1192, Japan.

§Institute for Frontier Science Initiative (InFiniti), Kanazawa University, Kakuma-machi, Kanazawa, Ishikawa 920-1192, Japan.

Contents

1. Experimental

2. Photo-stable inverted OSC reported by our rese arch group

3. AFM images of ZnO films

4. XPS analysis

5. I-V measurements of $\mathrm{ZnO}$ films

6. Thickness values of $\mathrm{ZnO}$ films

7. Summarized photovoltaic properties

8. Changes of typical $J-V$ characte ris tics with photo-irradiation time

9. Changes of $R_{\mathrm{Zno}}$ resistance with photo-irradiation time

10. Wate r-contact angle meas urement and work function values of $\mathrm{ZnO}$ films

11. XPS spectra of trime thoxy[3-(me thylamino)propyl] silane-tre ate $\mathrm{ZnO}^{100}{ }^{10 \mathrm{~nm}}$

12. Methyl trime thoxys ilane-tre ated $\mathrm{ZnO}$ base d $i$-OSC 


\section{Expe rimental}

\section{1-1. Mate rials}

Zinc acetylacetonate hydrate $\left(\mathrm{Zn}(\mathrm{AcAc})_{2}, 99.995 \%\right.$, trace metals basis), regioregular P3HT (MW 42,000), and 1,2-dichlorobenzene (DCB) were purchased from Sigma-Aldrich, Japan. A PEDOT:PSS dispersion in water (Clevios P) (1.3 wt\%) was purchased from H. C. Starck. The indium tin oxide (ITO) substrates (sheet resistance $=10 \Omega \mathrm{sq}$ ) and Au wires were purchased from Furuuchi Chemical Corporation. $\mathrm{PC}_{61} \mathrm{BM}$ was purchased from Frontier Carbon Corporation, Japan. Trimethoxy[3(methylamino)propyl]silane was purchased form Tokyo Chemical Industry Co., Ltd. All chemicals were used without further purification.

\section{1-2. Fabrication of $\mathrm{ZnO}$ films}

An ITO-coated glass substrate was cleaned by ultrasonication in isopropanol. The $\mathrm{ZnO}$ precursor solution was prepared by dissolving $\mathrm{Zn}(\mathrm{AcAc})_{2}(95 \mathrm{mg})$ in 2-methoxyethanol $(1.0 \mathrm{~mL})$ with acetyl acetone $(120 \mu \mathrm{L})$. A $\mathrm{ZnO}$ layer was prepared by spin coating of the precursor solution (1000 rpm, 60 s) and subsequent thermal annealing for $60 \mathrm{~min}$ under air atmosphere to control the relative humidity to be less than $30 \%$. For preparation of $\mathrm{ZnO}^{100}{ }_{10 \mathrm{~nm}}$, the precursor solution was diluted 10 times with isopropanol before spin-coating on ITO substrates.

\section{1-3. SAM-treatment of ZnO films}

$\mathrm{ZnO}^{100}{ }_{10 \mathrm{~nm}}$ films were cleaned by ultrasonication for 3 minutes in isopropanol. Then, the $\mathrm{ZnO}^{100}{ }_{10 \mathrm{~nm}} \mathrm{~S}$ were activated using a UV/ozone treatment for 30 second. A self-assembled monolayer (SAM) was formed on the cleaned substrates by immersing in a toluene solution of corresponding trimethoxysilane molecules $(50 \mathrm{mM})$ for $15 \mathrm{~min}$ at room temperature. The treated $\mathrm{ZnO}{ }^{100}{ }_{10 \mathrm{~nm}}$ films were rinsed with pure toluene and acetone. Following the final rinse step, the substrate was annealed on a hot plate at $100^{\circ} \mathrm{C}$ for 5 minutes under $\mathrm{N}_{2}$ atmosphere, and then the substrate was thoroughly washed with acetone.

\section{1-4. Fabrication of $i$-OSCs and $J-V$ meas ure ments}

An ODB solution of the active materials (regioregular P3HT and $\mathrm{PC}_{61} \mathrm{BM}, 1.25: 1,30 \mathrm{~g} / \mathrm{L}$ ) was spin-coated onto the prepared ITO/ZnO substrate at $700 \mathrm{rpm}$ for $40 \mathrm{~s}$. After the spin coating, the resulting film (thickness; $\sim 200 \mathrm{~nm}$ ) was solvent-annealed for $40 \mathrm{~min}$ in a closed container with ODB. 
A PEDOT:PSS (Clevios ${ }^{\circledR}$ P) hole transporting layer was fabricated by spin coating at $2000 \mathrm{rpm}$ for $60 \mathrm{~s}$. An Au electrode was deposited by thermal evaporation under vacuum (approximately $10^{-2} \mathrm{~Pa}$ ) through a metal mask (active area: $1.0 \mathrm{~cm}^{2}$ ). Finally, the device covered with sealing film (Cellel, Kureha Extech) was thermo-compressed at $30 \mathrm{~N} \mathrm{~m}^{-2}$ for $30 \mathrm{~s}$. All fabrication steps except the Au deposition step were performed in an $\mathrm{N}_{2}$-air mixed atmosphere to control the relative humidity to less than $30 \%$. The $J-V$ characteristics of the device were measured under simulated solar illumination $\left(\mathrm{AM} 1.5,100 \mathrm{~mW} / \mathrm{cm}^{2}\right)$ from a solar simulator based on a $150 \mathrm{~W}$ Xe lamp. The light source was a SAN-EI Electric XES-40S1 solar simulator, which was calibrated with a standard silicon photovolta ic detector. The $J-V$ measurements were performed under ambient conditions. The active area of the device was defined by using a $1.0 \mathrm{~cm}^{2}$ photo mask.

\section{1-5. Analytical measurements}

ATR-IR spectra were recorded on FT/IR-460plus (JASCO Corporation). AFM images were measured with a SII SPI3800N AFM apparatus. WF values were measured by using Trek model 320C electrostatic voltmeter with Kelvin probe unit. XPS analysis were performed by using Shimadzu AXIS-ULTRA DLDXPS apparatus. AC-impedance measurements were carried out using E4980A precision LCR meter (Agilent) under simulated sunlight irradiation. The frequency range was from $20 \mathrm{~Hz}$ to $1 \mathrm{MHz}$, the alternating signal magnitude was $5 \mathrm{mV}$ and $\mathrm{DC}$ bias was $0 \mathrm{~V}$. The data obtained were fitted with Scribner Associates Z-VIEW software v3.1 using the appropriate equivalent circuits. Water contact angles were observed using DMs-200 (Kyowa Interface Science Co. Ltd.). 
2. Photo-s table inverted OSC reported by our rese arch group

(a)
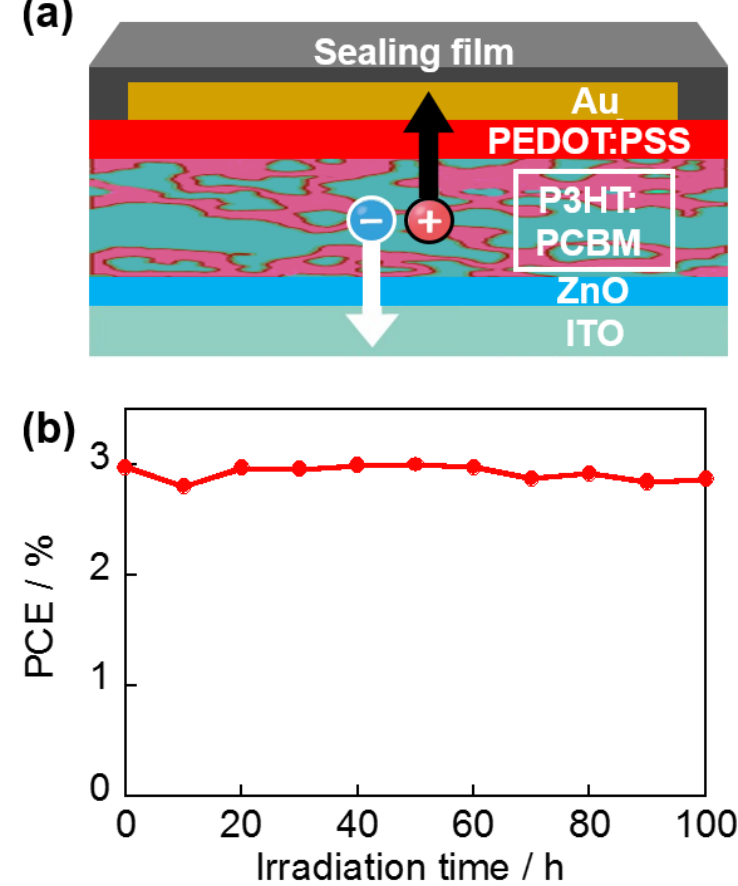

Figure S1. Structure of photo-stable $i$-OSC device reported by our research group (a) and changes of PCE of the $i$-OSC device with photo-irradiation time under ambient conditions (AM1.5G, 100 $\left.\mathrm{mWcm}^{-2}\right)(\mathrm{b})$.

\section{AFM images of ZnO films}
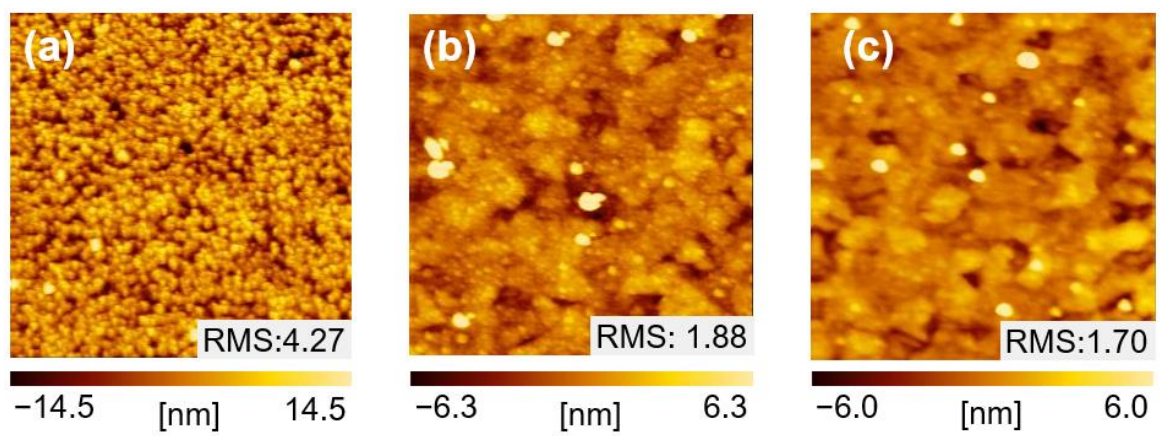

Figure S2. AFM images of $\mathrm{ZnO}$ films prepared at different annealing temperatures $\left(\mathrm{a}: 50^{\circ} \mathrm{C}, \mathrm{b}\right.$ : $\left.100^{\circ} \mathrm{C}, \mathrm{c}: 250^{\circ} \mathrm{C}, 5 \mu \mathrm{m} \times 5 \mu \mathrm{m}\right)$. 


\section{XPS analys is}
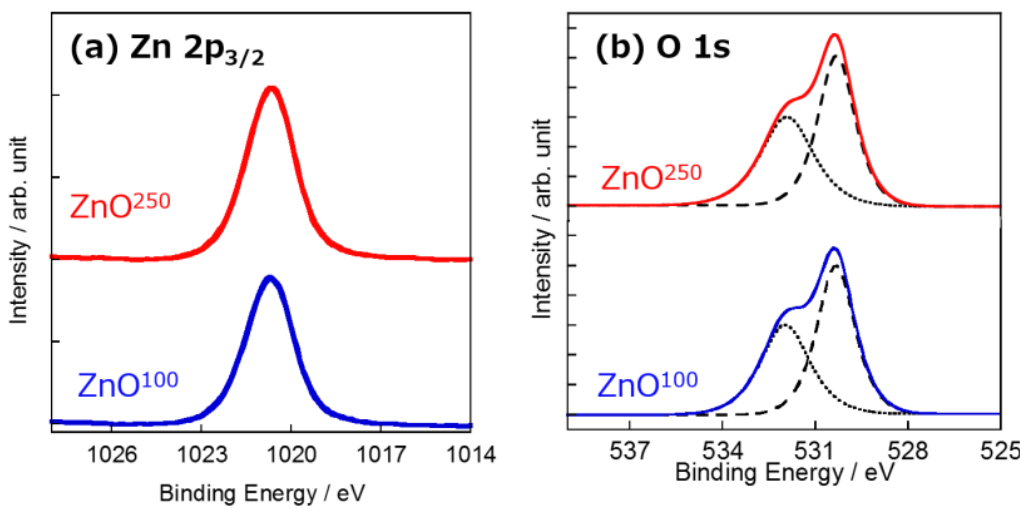

Figure S3. XPS analysis of $\mathrm{Zn} 2 \mathrm{p}_{3 / 2}$ (a) and $\mathrm{O} 1 \mathrm{~s}$ (b) core level spectra of $\mathrm{ZnO}^{100}{ }_{80 \mathrm{~nm}}$ and $\mathrm{ZnO}^{250}$.

\section{I-V meas ure ments of $\mathrm{ZnO}$ films}

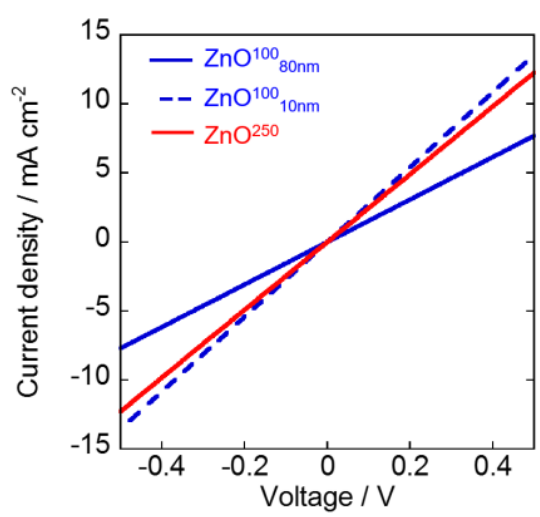

Figure S4. $J-V$ characteristics of $\mathrm{ZnO}$ films sandwiched by ITO and Ag electrodes $(\mathrm{ITO} / \mathrm{ZnO} / \mathrm{Ag})$. 


\section{Thickness values of $\mathrm{ZnO}$ films}

Table S1. Thickness values of $\mathrm{ZnO}$ films prepared at different thermal annealing temperatures and concentrations of precursor solution.

\begin{tabular}{ccc}
\hline $\begin{array}{c}\text { Annealing } \\
\text { Temperature } /{ }^{\circ} \mathrm{C}\end{array}$ & $\begin{array}{c}\text { Concentration of } \\
\text { precursor solution } / \mathrm{M}\end{array}$ & Thickness / nm \\
\hline 250 & 0.35 & 30 \\
150 & 0.35 & 60 \\
100 & 0.35 & 80 \\
100 & 0.035 & 10 \\
\hline
\end{tabular}

\section{Summarized photovoltaic properties}

Table S2. Summary of photovoltaic properties of $i$-OSCs based on $\mathrm{ZnO}^{250}$, $\mathrm{ZnO}^{100}{ }_{80 \mathrm{~nm}}$, and $\mathrm{ZnO}^{100}{ }_{10 \mathrm{~nm}}$.

\begin{tabular}{c|c|cccc}
\hline $\begin{array}{c}\text { ZnO Annealing } \\
\text { Temp } /{ }^{\circ} \mathrm{C}\end{array}$ & $\begin{array}{c}\text { Thickness } \\
/ \mathrm{nm}\end{array}$ & $\begin{array}{c}J_{\mathrm{SC}} \\
/ \mathrm{mAcm}^{-2}\end{array}$ & $\begin{array}{c}V_{\mathrm{OC}} \\
/ \mathrm{V}\end{array}$ & $\mathrm{FF}$ & PCE $/ \%$ \\
\hline 250 & 30 & $9.0( \pm 0.1)$ & $0.56( \pm 0.0)$ & $0.61( \pm 0.0)$ & $3.1( \pm 0.1)$ \\
100 & 80 & $6.3( \pm 0.2)$ & $0.57( \pm 0.0)$ & $0.60( \pm 0.0)$ & $2.1( \pm 0.1)$ \\
100 & 10 & $9.1( \pm 0.2)$ & $0.57( \pm 0.0)$ & $0.61( \pm 0.0)$ & $3.1( \pm 0.1)$ \\
\hline
\end{tabular}




\section{Changes of typical $J-V$ characteris tics with photo-irradiation time}
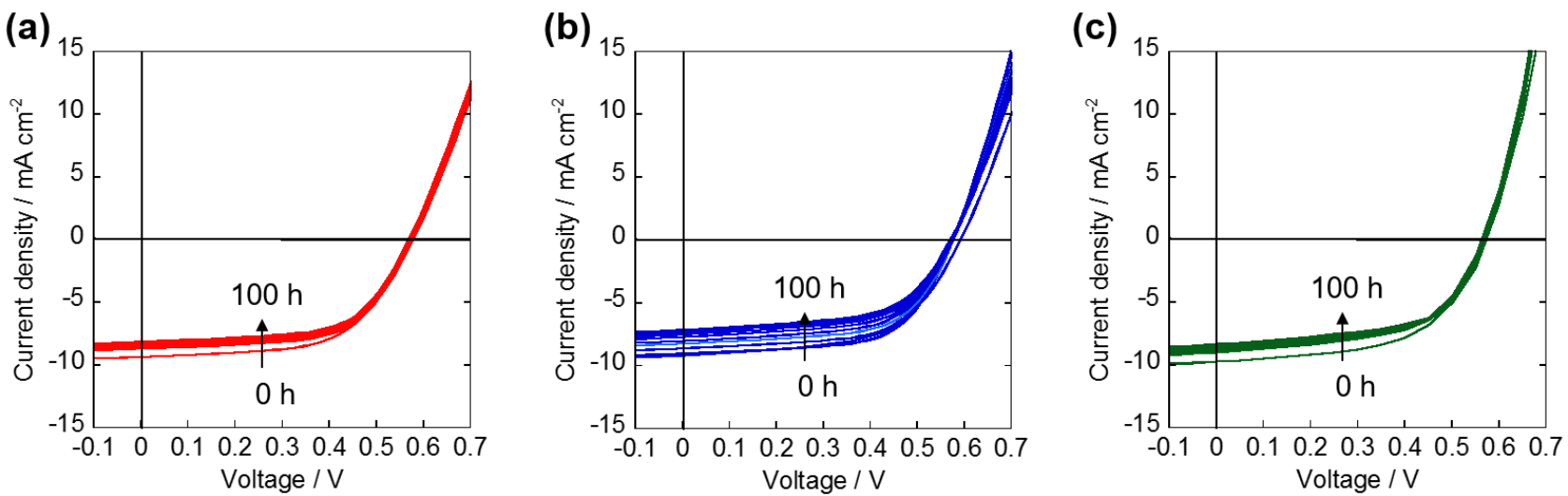

Figure S5. Changes of typical $J$ - $V$ characteristics of $i$-OSCs based on $\mathrm{ZnO}^{250}$ (a), $\mathrm{ZnO}^{100}{ }_{10 \mathrm{~nm}}$ (b), and SAM-treated $\mathrm{ZnO}^{100}{ }_{10 \mathrm{~nm}}(\mathrm{c})$ with photo-irradiation time $(0-100 \mathrm{~h})$.
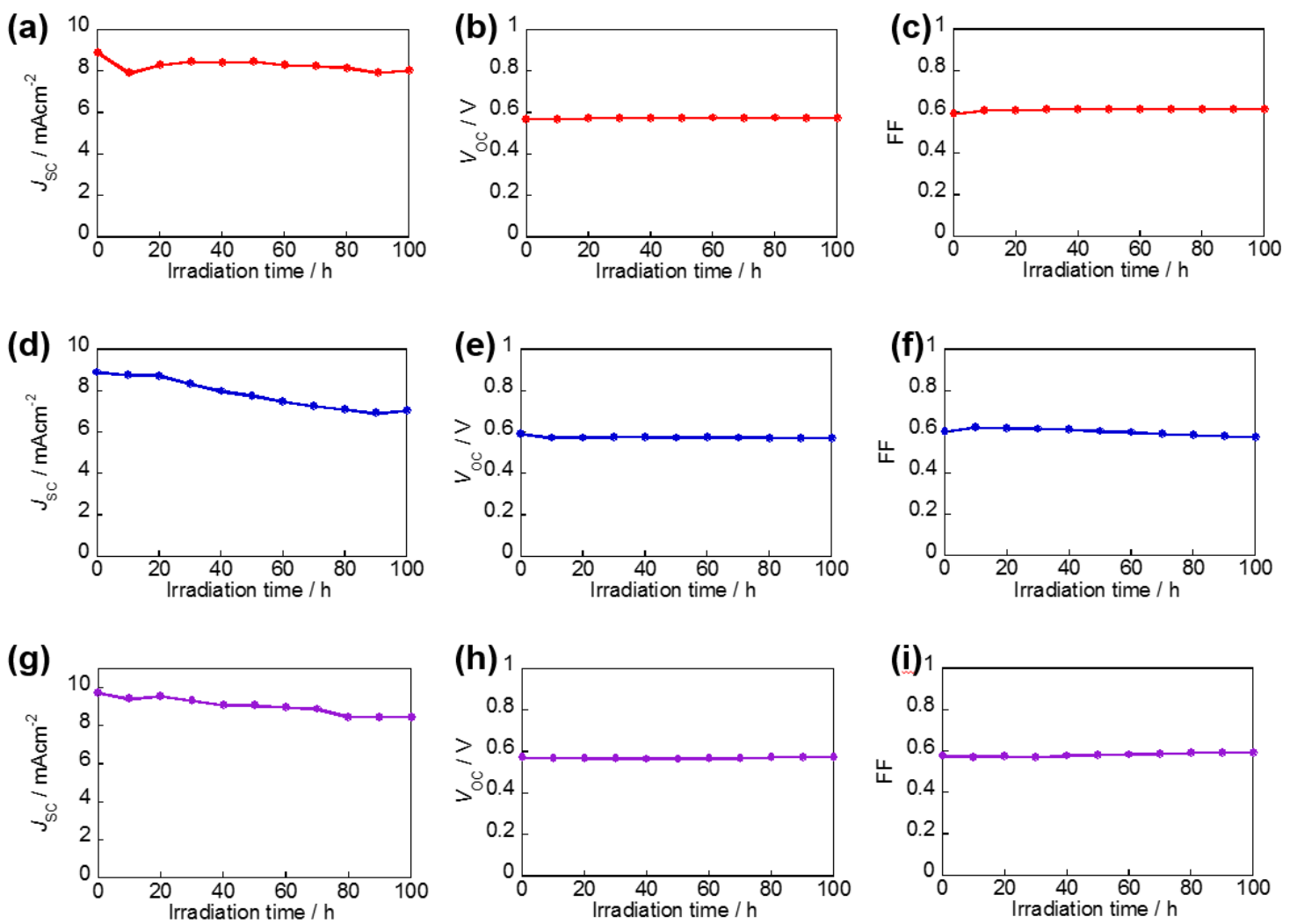

Figure S6. Changes of $J_{\mathrm{SC}}, V_{\mathrm{OC}}$, and $\mathrm{FF}$ of $i$-OSCs based on $\mathrm{ZnO}^{250}(\mathrm{a}, \mathrm{b}, \mathrm{c}), \mathrm{ZnO}^{100}{ }_{10 \mathrm{~nm}}(\mathrm{~d}$,e,f), and SAM-treated $\mathrm{ZnO}^{100}{ }_{10 \mathrm{~nm}}(\mathrm{~g}, \mathrm{~h}, \mathrm{i})$ with photo-irradiation time $(0-100 \mathrm{~h})$. 


\section{Changes of $R_{\mathrm{Zno}}$ resistance with photo-irradiation time}
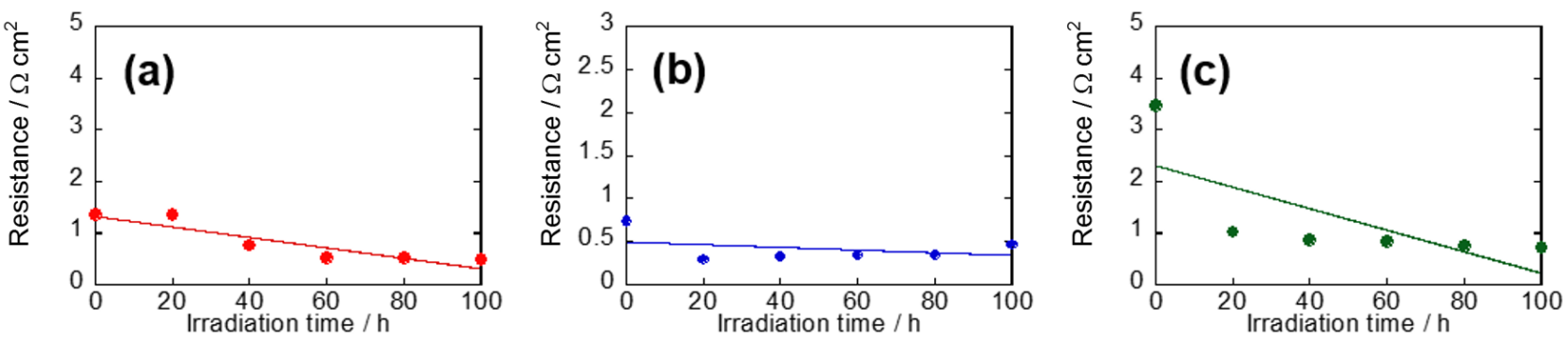

10. Wate r-contact angle meas ure ment and work function values of $\mathrm{ZnO}$ films
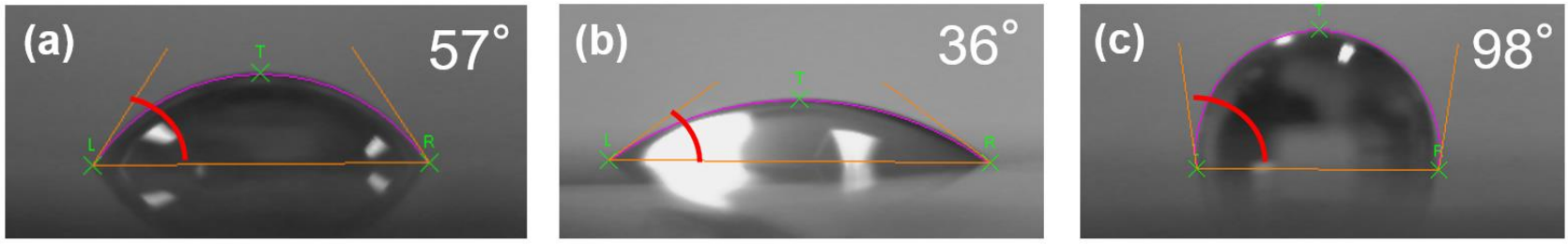

Figure S8. Water-contact angle measurement of $\mathrm{ZnO}^{250}$ (a), $\mathrm{ZnO}^{100} 80 \mathrm{~nm}$ (b), and 3(methylamino) propylsila ne-treated $\mathrm{ZnO}^{100} 80 \mathrm{~nm}(\mathrm{c})$

11. XPS spectra of trime thoxy[3-(methylamino)propyl] silane-tre ate $\mathrm{ZnO}^{100}{ }_{10 \mathrm{~nm}}$
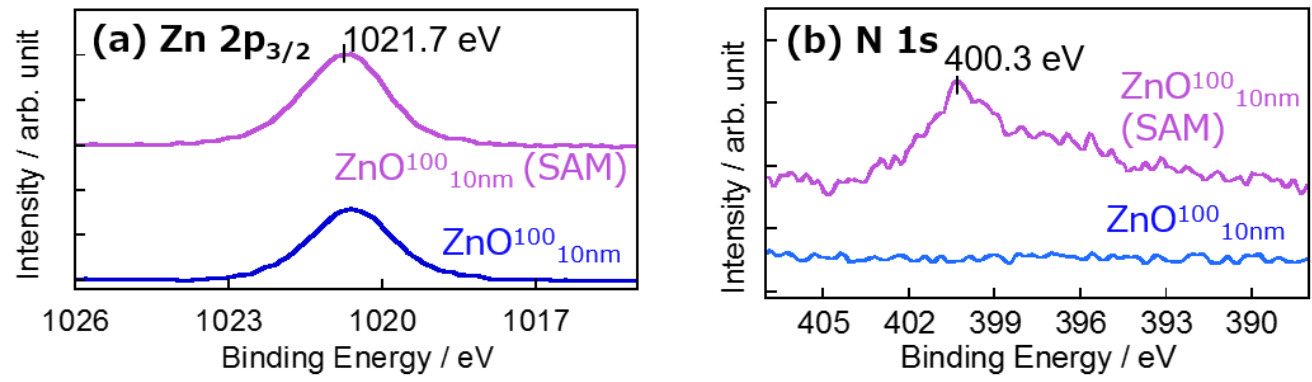

Figure S9. XPS analysis of $\mathrm{Zn} 2 \mathrm{p}_{3 / 2}$ (a) and $\mathrm{N}$ 1s (b) core level spectra of trimethoxy[3(methylamino)propyl]silane-treated $\mathrm{ZnO}^{100}{ }_{10 \mathrm{~nm}}$. 


\section{Methyl trime thoxysilane-tre ated $\mathrm{ZnO}$ based $i$-OSC}

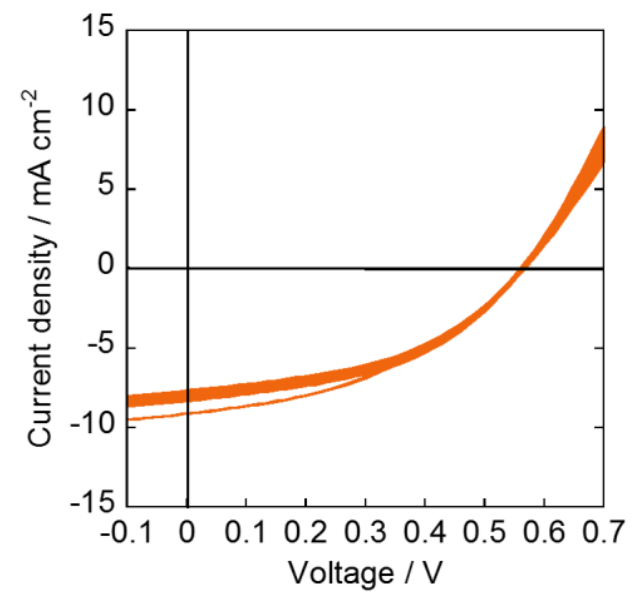

Figure S10. Changes of typical $J-V$ characteristics of $i$-OSCs based on methyl trimethoxysilanetreated $\mathrm{ZnO}^{100}{ }_{10 \mathrm{~nm}}$ with photo-irradiation time $(0-100 \mathrm{~h})$.

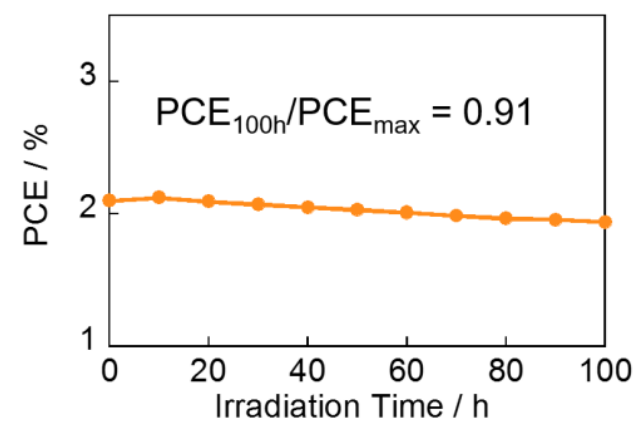

Figure S11. Changes of PCE value of $i$-OSCs based on methyl trimethoxysilane-treated $\mathrm{ZnO}^{100}{ }^{10 \mathrm{~nm}}$ with photo-irradiation time $(0-100 \mathrm{~h})$. 